\title{
Immunomodulation of NK Cells by lonizing Radiation
}

\begin{abstract}
Jiarui Chen ${ }^{1+}$, Xingyu Liu ${ }^{1 \dagger}$, Zihang Zeng ${ }^{1}$, Jiali Li $^{1}$, Yuan Luo ${ }^{1}$, Wenjie Sun ${ }^{1}$, Yan Gong ${ }^{2,3}$, Junhong Zhang ${ }^{1,4,5}$, Qiuji Wu ${ }^{1,4,5 *}$ and Conghua Xie ${ }^{1,4,5 *}$

${ }^{1}$ Department of Radiation and Medical Oncology, Zhongnan Hospital of Wuhan University, Wuhan, China, ${ }^{2}$ Department of Biological Repositories, Zhongnan Hospital of Wuhan University, Wuhan, China, ${ }^{3}$ Human Genetics Resource Preservation Center of Hubei Province, Human Genetics Resource Preservation Center of Wuhan University, Zhongnan Hospital of Wuhan University, Wuhan, China, ${ }^{4}$ Hubei Key Laboratory of Tumor Biological Behaviors, Zhongnan Hospital of Wuhan University, Wuhan, China, ${ }^{5}$ Hubei Cancer Clinical Study Center, Zhongnan Hospital of Wuhan University, Wuhan, China
\end{abstract}

Natural killer (NK) cells play a critical role in the antitumor immunity. lonizing radiation (IR) has a pronounced effect on modifying NK cell biology, while the molecular mechanisms remain elusive. In this review, we briefly introduce the anti-tumor activity of NK cells and summarize the impact of IR on NK cells both directly and indirectly. On one hand, low-dose ionizing radiation (LDIR) activates NK functions while high-dose ionizing radiation (HDIR) is likely to partially impair NK functions, which can be reversed by interleukin (IL)-2 pretreatment. On the other hand, NK functions may be adjusted by other immune cells and the alternated malignant cell immunogenicity under the settings of IR. Various immune cells, such as the tumor-associated macrophage (TAM), dendritic cell (DC), regulatory T cell (Treg), myeloid-derived suppressor cell (MDSC), and tumor exhibited ligands, such as the natural killer group 2 member D ligand (NKG2DL), natural cytotoxicity receptors (NCR) ligand, TNF-related apoptosis-inducing ligand-receptor (TRAIL-R), and FAS, have been involved in this process. Better understanding the molecular basis is a promising way in which to augment NK-cell-based antitumor immunity in combination with $I R$.

Keywords: NK cell, ionizing radiation, tumor, immune response, immunotherapy

\section{INTRODUCTION}

Natural killer (NK) cells, belonging to the innate lymphoid cells (1), are important effectors of tumor immunosurveillance. They play a major role in recognizing and killing tumor cells as well as secreting chemokines and cytokines to regulate adaptive immune response (2). NK cells are phenotypically defined by the expression of CD56 and the lack of CD3 (3) and can classically be divided into two populations: a CD56 $6^{\text {bright }} \mathrm{CD} 16^{\mathrm{dim}}$ population and a $\mathrm{CD} 56^{\mathrm{dim}} \mathrm{CD} 16^{\text {bright }}$ population. The $\mathrm{CD} 56^{\text {bright }} \mathrm{CD} 16^{\mathrm{dim}}$ population are immature cells, characterized by cytokines production and immunoregulation; CD56 ${ }^{\text {dim }} \mathrm{CD} 16^{\text {bright }}$ population are mature, specialized in perforin release and target killing, and are also capable of antibody-dependent cellular cytotoxicity (ADCC) (4).

\section{ANTI-TUMOR ACTIVITY OF NK CELLS}

NK cell functions are determined by a balance between the activity of the activating and inhibitory receptors, which are tightly regulated by transcriptional programs and post-transcriptional 
regulations (5). The activating receptors, notably the natural cytotoxicity receptors (NCRs), including NKp46 (6), NKp30 (7), NKp44 (8), natural killer group 2 member D (NKG2D) (9), DNAX accessory molecule-1 (DNAM-1), and CD244, recognize ligands expressed on tumor cells. For signaling, NCRs stimulate the phosphorylation of immunoreceptor tyrosinebased activation motifs (ITAMs) that engage with adaptor proteins, giving rise to downstream signaling propagation, manifested by phosphoinositide 3-kinase (PI3K) and VAV$2 / 3$ (10) activation. NKG2D assembles with the adaptor molecule DANX activation protein 10 (DAP10), resulting in the phosphoinositide 3-kinase/protein kinase $\mathrm{B} / \mathrm{mammalian}$ target of rapamycin (PI3K/AKT/mTOR) signaling cascade stimulation through phosphorylating the cytoplasmic Y-X-X-M motif of DAP10 (11). On the other hand, DNAM-1 couples with the lymphocyte function-associated antigen 1 (LFA-1), ultimately contributing to the activation of extracellular regulated kinase (ERK)/AKT (12). Initiated by the engagement of $2 \mathrm{~B} 4$, the receptor CD244 is transferred to the lipid raft, paralleled with cytoplasmic immunoreceptor tyrosine-based switch motifs (ITSMs) phosphorylation, triggering the interaction with SLAM-associated protein (SAP), SH3-binding protein 2 (3BP2), and other signaling molecules (13). Consequently, the downstream signaling cascades bring about a strong NK cell activation via calcium mobilization, degranulation and effector proteins, and interferon (IFN)- $\gamma$ and granulocyte macrophage colony-stimulating factor (GM-CSF) secretion (10-13). The inhibitory receptors, including the killer cell immunoglobulin-like receptors (KIRs) (14) and the natural killer group 2 member A (NKG2A) (15), associate with major histocompatibility complex class I (MHC I) molecules expressed on target cells and initiate immunoreceptor tyrosinebased inhibitory motif (ITIM)-mediated inhibitory signaling pathway (16).

NK cells can directly eliminate tumor cells through multiple ways: first, NK cells release cytotoxic granules containing perforin and granzymes, leading to cell lysis $(2,17)$. Meanwhile, the production of cytokines such as IFN- $\gamma$ (18) and tumor necrosis factor (TNF)- $\alpha$ (19) augments NK cell cytotoxicity. Second, NK cells express TNF family members such as the TNF-related apoptosis-inducing ligand (TRAIL) and FAS ligand (FASL), which interact with their receptors respectively and elicit tumor cell apoptosis (20-22). In addition, ADCC, triggered by $\mathrm{Fc} \gamma$ receptor CD16, enables NK cell degranulation against target cells (23).

\section{NK CELL EXHAUSTION IN TME}

The tumor microenvironment (TME), however, usually brings about NK cell exhaustion. Dysregulation of checkpoint ligands, suppressive immune cells, such as the regulatory T cell (Treg), myeloid-derived suppressor cell (MDSC), and tumor-associated macrophage (TAM), tumor-associated exosomes, transforming growth factor (TGF)- $\beta$ cytokine secretion, and hypoxia might restrict NK cell function in assorted ways while the molecular mechanisms remain largely undiscovered (15).

\section{MODULATION OF NK CELL ACTIVITY BY IR}

Ionizing radiation (IR), one of the key cornerstones in cancer treatment, causes double-strand DNA breaks, contributing to tumor cell death. Moreover, IR elicits specific molecular changes sensed by the immune system either within tumors or in normal tissues, rendering tumor cells either more susceptible or more tolerant to immune attack (24). It has previously been demonstrated that IR boosts the immune response by augmenting the antigenicity and the adjuvanticity of malignant cells and by interacting with the TME (25). Meanwhile, IR can mediate robust immunosuppressive effects through altering particular ligands [e.g., programmed death ligand 1 (PD-L1) $(26,27)$, NKG2D (28)], secreting suppressive cytokines [e.g., TGF- $\beta$ (29), interleukin (IL)-6 (30), and IL-10 (31)], surging the recruitment of immunosuppressive cells [e.g., Tregs (31), MDSCs (32), and TAMs (30)] and aggravating hypoxic TME (33).

The impacts of IR on immune cells, such T cells, macrophages, and dendritic cells (DCs), have been extensively studied. Likewise, the effect of IR on NK cells has attracted increased attention in recent years. In this review, we summarize the impact of IR on NK cells and its potential significance in antitumoral immune response (Figure 1). It could be a promising strategy to enhance $\mathrm{NK}$ cell cytotoxicity and reverse NK cell exhaustion.

\section{Direct Regulation of NK Cell Functions by IR}

High-dose ionizing radiation (HDIR) is detrimental, causing cell apoptosis, while low-dose ionizing radiation (LDIR) can benefit living organisms via stimulating immune competence $(34,35)$. In vitro LDIR at 75-150 mGy was observed to have a most pronounced effect on expansion and secretion of NK cell effector proteins, such as IFN- $\gamma$ and TNF- $\alpha$, possibly through the p38-mitogen-activated protein kinase (MAPK) pathway, which could be visibly potentiated by low dose of pre-radiation IL2 treatment $(36,37)$. Alteration of activating receptors are not observed when NK cells undergo LDIR, suggesting that an independent regulation of NK cell cytotoxicity is mainly due to intrinsic cell proliferation and effector protein expression. Similar results have been obtained with tumor-bearing rats exposed to low-dose total-body irradiation (TBI) ( 0.1 or 0.2 Gy $\mathrm{X}$ rays), leading to the suppression of experimental tumor metastases along with the stimulation of NK cell cytolytic functions postirradiation $(38,39)$. Moreover, it has also been reported that levels of phosphorylation of ataxia telangiectasia mutated (ATM), a marker of DNA damage response, increased during NK cell activation, indicating IR might regulate NK function through the DNA damage pathway (40). The nuclear factor kappa B (NF-B) signaling activation initiated by IR may exert a positive potential on granzyme B gene transcription as well as perforin gene expression $(41,42)$ and autophagy triggered by IR holds a decisive place in NK cell differentiation (43). However, the superb irradiation doses motivating these NK cell functions remain unearthed. 

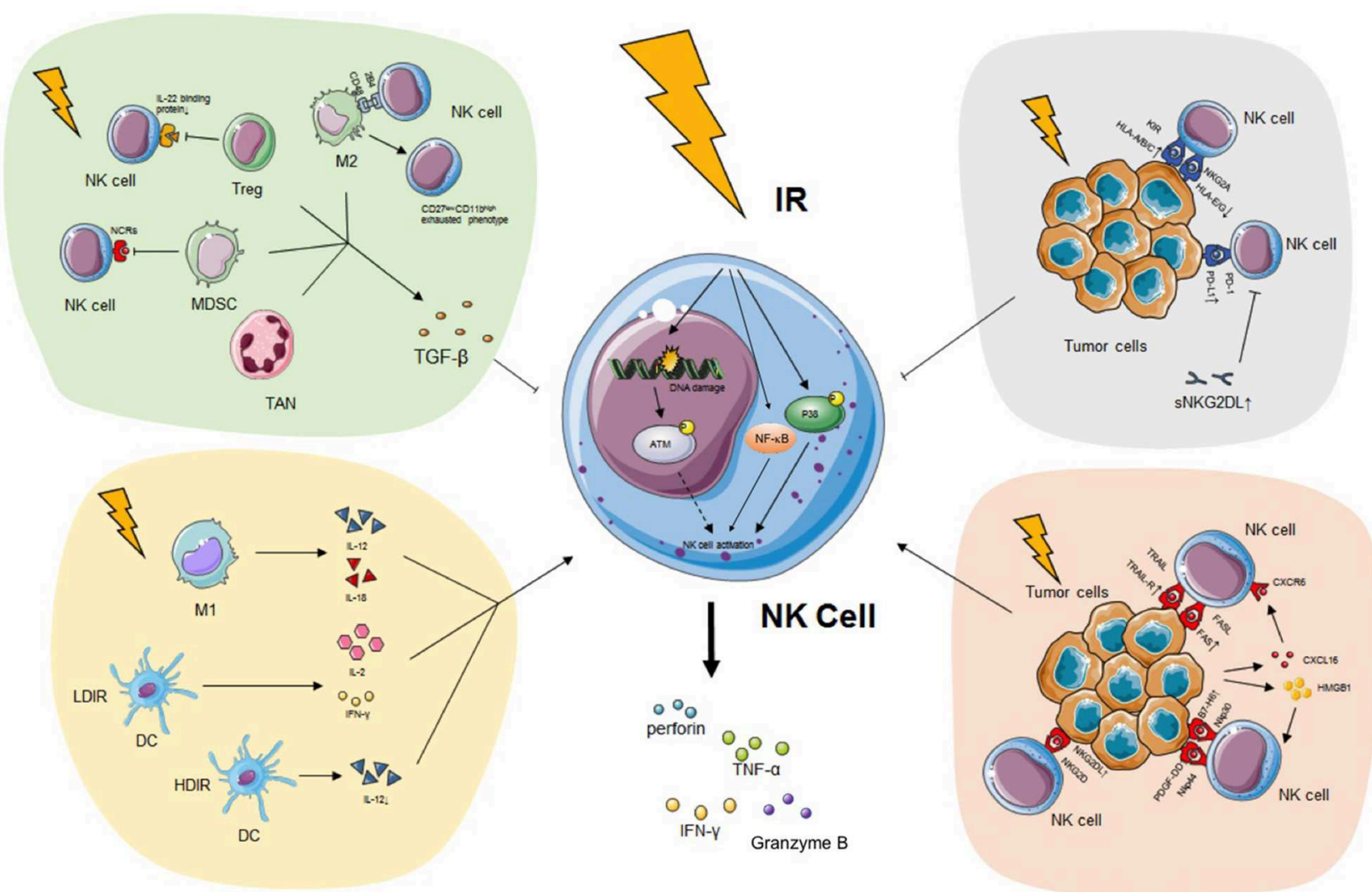

FIGURE 1 | The impact of IR on NK cell. IR has a pronounced effect on modifying NK cell biology both directly and indirectly. On the one hand, IR induces the secretion of IFN- $\gamma$, TNF- $\alpha$, perforin, and granzyme B of NK cells possibly through the p38-MAPK, ATM, and NF-кB pathway without alteration of activating receptors. On the other hand, IR programs the differentiation of classical activated macrophage (M1), which releases immunostimulatory IL-12 or IL-18 and triggers NK cytotoxicity. DC exposed to LDIR produces enhanced IL-2 and IFN- $\gamma$ which promote NK functions while DC exposed to HDIR secretes less IL-12. IR also leads to the recruitment and activation of pro-tumor TAN phenotype (N2), alternatively activated macrophage (M2), Treg and MDSC which secrete TGF- $\beta$ and impair NK activity. Finally, tumor expressed ligands, such as NKG2DL, TRAIL-R, and FAS, are upregulated during IR, enhancing the recognition of malignant cells by NK cells. However, PD-L1, classical HLA class I, sNKG2DL are also upregulated during IR, impairing the immunogenicity of tumor cells and NK cell recognition. See the main text for details. IR, ionizing radiation; NK cell, natural killer cell; IFN- $\gamma$, interferon- $\gamma$; TNF- $\alpha$, tumor necrosis factor- $\alpha$; MAPK, mitogen-activated protein kinase; ATM, ataxia telangiectasia mutated; NF-kB, nuclear factor kappa B; IL, interleukin; DC, dendritic cell; LDIR, low-dose ionizing radiation; HDIR, high-dose ionizing radiation; TAN, tumor-associated neutrophil; Treg, regulatory T cell; MDSC, myeloid-derived suppressor cell; TGF- $\beta$, transforming growth factor- $\beta$; NKG2DL, natural killer group 2 member D ligand; TRAIL-R, TNF-related apoptosis-inducing ligand-receptor; PD-L1, programmed death ligand 1; HLA, human leukocyte antigen; sNKG2DL, soluble natural killer group 2 member D ligand.

As in the case of HDIR (single dose $\geq 1.0 \mathrm{~Gy}$ ), although NK cells showed partially impaired functions (44), IL-2 pretreated NK cells were more radioresistant, with their cytotoxicity being not abrogated following 30 Gy IR (45). Fractionated irradiation, $15 \mathrm{~Gy} \times 2$ applied at diverse intervals as well as $2.5 \mathrm{~Gy} \times$ 4 applied at the same intervals, resulted in elevations of adenosine triphosphate (ATP) level and NK cell cytotoxicity compared to single irradiated controls delivered with $30 \mathrm{~Gy}$ and $10 \mathrm{~Gy}$, which suggested that fractionated irradiation might be conducive to maintain NK cell functions as compared to singledose irradiation, with the mechanism remaining uncovered (46). Taken together, the regulation of NK cell functions by ionizing radiation is strongly affected by the irradiation doses. LDIR tends to stimulate the NK cell cytotoxicity, and HDIR, especially the single-dose irradiation, is more likely to undermine the NK function, which can be reversed by IL-2 pretreatment. While optimal fraction schemes, IL-2 pretreatment and irradiation doses that are favorable to NK functions remain to be determined, the research into molecular mechanisms will with no doubt promote the utilization of NK cell-derived therapies in cancer.

\section{NK Cell Function Adjusted by Other Immune Cells Tumor-Associated Macrophages (TAMs)}

Macrophages are highly plastic cells that can be polarized toward classically activated phenotype (M1) and alternatively activated phenotype (M2). M1-like macrophages perform a dominant role in fighting against bacterial infections and malignant tumors while M2-like macrophages are proficient effectors in tissue remodeling, angiogenesis, immune regulation, and tumor progression (47). LDIR (doses $\leq 2.0 \mathrm{~Gy}$ ) programmed 
TAMs toward an M1-like phenotype $(48,49)$ characterized by immunostimulatory IL-12 or IL-18 release and NF- $\mathrm{\kappa B}$ pathway activation $(50,51)$, triggering cytolytic NK cell function (52). On the contrary, HDIR (doses $\geq 2.0 \mathrm{~Gy}$ ) promoted M2-like phenotype activation (53-55). In this setting, M2-derived TGF$\beta$ decreased tumor infiltrating NK expression of Ki-67 as well as secretion of IFN- $\gamma$ and TNF- $\alpha$ (56). Furthermore, M2 induced a CD27 ${ }^{\text {low }} \mathrm{CD} 11 b^{\text {high }}$ exhausted NK cell phenotype (57). Finally, tumor-associated macrophages expressed higher levels of CD48, mediating transient activation and subsequent dysfunction of NK cells via CD48-2B4 interactions (58). Therefore, IR may indirectly regulate NK cell activity via shaping the phenotypes of TAMs, and we may bring about promising anti-tumor effect of NK cells by combining IR with M2 population reversion.

\section{Regulatory T Cells (Tregs)}

Tregs are observed to maintain immune tolerance and hinder suppression of infections and cancers by inhibiting effector $\mathrm{T}$ cells, B cells and NK cells $(59,60)$. The capacity of IR to induce TGF- $\beta$ signaling (61) and vascular endothelial growth factor A (VEGFA) secretion (62) in the tumor environment favored the expansion of Treg cells. For instance, a local tumor irradiation of $15 \mathrm{~Gy}$ promoted Treg accumulation in C57BL/6 mice bearing B16-OVA murine melanoma while fractionated $2 \times 7.5$ Gy and 3 $\times 5$ Gy maintained lower Treg numbers (63). Likewise, $2 \mathrm{~Gy} \gamma$ radiation TBI significantly increased the frequency of Treg cells in peripheral blood, lymph nodes, spleens, and thymus in mice (64). However, the systemic surge of Tregs has been observed to suppress NK-cell-mediated cytotoxicity through reducing IL-22 binding protein that is known to inhibit tumor cell proliferation (65). Moreover, Tregs selectively expressed membrane-bound TGF- $\beta$, downregulating NKG2D expression and impairing NKcell-mediated tumor immunosurveillance (66). Finally, Tregs augmented endonuclease $\mathrm{G}$ (EndoG) expression and led to NK cell senescence as a consequence of telomerase reverse transcriptase (TERT) mRNA alternative splicing and telomerase inhibition (67). Thus, the application of chemopreventive drugs makes it possible to block Tregs at an earlier stage and to preserve activity of NK cells.

\section{Myeloid-Derived Suppressor Cells (MDSCs)}

MDSCs contribute to the immune escape of pathogens and malignant tumors by restraining $\mathrm{T}$ cells and NK cells as well as maturation of DCs (68). IR boosted the secretion of IL-6 (69) and colony stimulating factor 1 (CSF1) (32) from irradiated cells, mediating robust chemotactic effects on MDSCs. A systemic

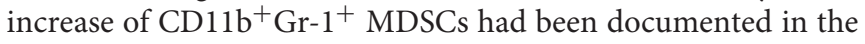
spleen, lung, lymph nodes, and peripheral blood when RM-1 and Myc-Cap implanted C57BL/6 mice were exposed to $5 \times$ 5 Gy hypofractionated radiotherapy (RT) depending on CSF1 pathway (32). Likewise, non-small cell lung cancer patients treated with RT ( $2.75 \mathrm{~Gy}$ in 24 fractions) preceding by low-dose cisplatin were intensively infiltrated with CD14 ${ }^{+} \mathrm{HLA}-\mathrm{DR}{ }^{\text {low }}$ and $\mathrm{CD} 14^{+} \mathrm{CD} 33^{+}$HLA-DR ${ }^{\text {low }}$ MDSCs (70). However, MDSCs have been observed to induce anergy of NK cells via membranebound TGF- $\beta$ and interaction with the NKp30 receptor (7173). Similar results have been obtained with cancer-expanded
MDSCs in a liver cancer-bearing murine model where NK cell functions were exacerbated, exhibiting as reduced degranulated cytotoxicity, NKG2D expression and IFN- $\gamma$ production both in vitro and in vivo (72). Finally, CD247, a key subunit of NCRs and CD16, was observed to be downregulated on the NK surface by MDSCs (74). Inspired by the previous findings, inhibiting the infiltration of MDSCs to TME as well as targeting MDSC-NK crosstalk may abrogate NK anergy and reject tumor progression more effectively.

\section{Dendritic Cells (DCs)}

DCs are the most potent antigen-presenting cells that prime a $\mathrm{T}$ cell response and regulate both the innate and adaptive immunity (75). Previous studies have demonstrated that LDIR (doses $\leq 0.2$ Gy) significantly enhanced IL- 2 and IFN- $\gamma$ production of DCs through ATM/NF- $\mathrm{BB}$ cascade $(76,77)$, stimulating NK cell survival, proliferation and cytotoxicity (78). On the other hand, mature dendritic cells exposed to HDIR (with doses ranging from 2 to 30 Gy) secreted less IL-12 (79), an essential contributor to perforin-mediated NK cell cytotoxicity and IFN- $\gamma$ production (80). Regarding these supreme investigations, we believe that LDIR is able to enforce NK-DC interaction, leading to more efficient tumor recognition and retardation by NK cells.

\section{Tumor-Associated Neutrophils (TANs)}

Neutrophils are the first line of defense against infection and inflammation while TANs tend to exert protumoral functions (81). IR-induced TGF- $\beta$ signaling in the tumor microenvironment led to the recruitment and activation of TANs with a pro-tumor phenotype (82), paralleled by facilitating NK cell dysfunction and preventing NK cells from mediating clearance of tumor cells (83), which can be overcome by the blockade of TGF- $\beta$.

To conclude, Tregs, MDSCs and TANs are likely to induce NK cell anergy when exposed to IR. TAMs and DCs, under the circumstance of LDIR, are inclined to activate NK cell functions, which will otherwise impair NK activity when treated with HDIR (Table 1).

\section{Immunoediting of Immunogenic Malignant Cells}

The recognition of malignant cells by NK cells could be altered after exposure to IR, partially through the modulation of tumor exhibited ligands, thus affecting malignant cell immunogenicity.

\section{NKG2D Ligands}

NKG2D is a major activating receptor expressed on all NK cells, and NKG2D ligands are usually restricted or deficient on normal tissues to escape autoimmune injury (84). In vitro, IR significantly upregulated NKG2D ligands in a time-dependent manner, rendering malignant cells more sensitive to NK cells (28, $85)$, which was probably ascribed to the DNA damage response pathway (86). However, discordances in NKG2D mRNA and surface protein expression levels were observed, reflecting differential transcriptional and post-transcriptional regulation of NKG2D expression (28). In line with these possibilities, 
TABLE 1 | Comparisons of LDIR and HDIR in response.

\begin{tabular}{|c|c|c|c|c|}
\hline Responses & LDIR & Dose ranges & HDIR & Dose ranges \\
\hline Direct effect on NK cells & $\begin{array}{l}\text { NK cell activation }(36,37) \\
\text { Tumor metastases suppression }(38,39)\end{array}$ & $\leq 0.2 \mathrm{~Gy}$ & NK cell cytotoxicity impaired $(44,45)$ & $\geq 1.0$ Gy \\
\hline TAM-NK interaction & $\begin{array}{l}\text { M1 differentiation, IL-12, IL-18 release (48-51) } \\
\text { NK cell activation (52) }\end{array}$ & $\leq 2.0$ Gy & $\begin{array}{l}\text { M2 recruitment, TGF- } \beta \text { secretion, } \\
\text { CD48 expression }(53-56) \\
\text { NK cell dysfunction }(57,58)\end{array}$ & $\geq 2.0$ Gy \\
\hline DC-NK interaction & $\begin{array}{l}\text { IL-2, IFN- } \gamma \text { secretion by DCs }(76,77) \\
\text { NK cell activation }(78)\end{array}$ & $\leq 0.2 \mathrm{~Gy}$ & $\begin{array}{l}\text { IL-12 less production by DCs }(79) \\
\text { NK cell cytotoxicity impaired ( } 80)\end{array}$ & 2-30 Gy \\
\hline
\end{tabular}

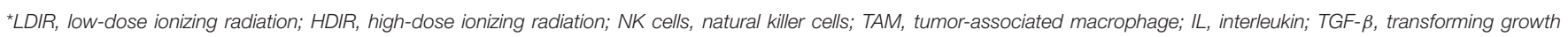
factor- $\beta$; $D C$, dendritic cell; IFN- $\gamma$, interferon $-\gamma$.

histone deacetylase (HDAC) inhibitors, modifying the posttranscriptional epigenetic, enhanced IR-induced NKG2D ligand expression and increased susceptibility of tumor cells to NK cells. In vivo, IR gave rise to survival benefit in glioma-bearing mice, which could be abrogated by an anti-NKG2D antibody (87). To summarize, IR modulates the expression of NKG2DLs in time- and dose- dependent manners, which could be targeted to enhance NK cell tumoricidal effect.

In addition to NKG2DL, a shed form of NKG2DL, s-NKG2DL, generally serves as an immunity inhibitor (88), binding to the NKG2D receptors and impairing NKG2D function (89). IR increased the expression of matrix metalloproteinase-2 (MMP2) and a disintegrin and metalloproteinase domain-containing protein-10 (ADAM10) in a dose-dependent manner, mediating proteolytic shedding of NKG2D. Altogether, IR induces the surface expression of NKG2DL as well as the shed form of NKG2DL, s-NKG2DL, efficiently, and the latter suppresses NK cell function, which could be reversed by the combination of IR and MMP inhibitors (90).

\section{NCRs Ligands}

Several tumor-associated ligands for NCRs have been observed, including galectin-3 and B7-H6 (a newly identified ligand in the B7 family) for NKp30 (91), mixed-lineage leukemia protein5 (MLL5), proliferating cell nuclear antigen (PCNA), nidogen1 (NID1), platelet-derived growth factor (PDGF) for NKp44 (92), and vimentin for NKp46. Galectin-3, a lately discovered $\beta$ galactoside-binding protein expressed on tumor cells (93), was described as NKp30 inhibitor, restraining NKp30-mediated NK functions and tumor escape elimination by NK cells $(93,94)$. Luckily, IR alone did not change galectin-3 expression (95). Another NKp30 activator, B7-H6, is widely expressed on tumor cells (96-98). Malignant cells were more sensitive to NK cell lysis as a consequence of B7-H6 upregulation in response to IR (99). Few studies concerning the effect of IR on NKp44 ligands. IR deposits onto tumor cells as a stress inducer, producing proangiogenic cytokines such as PDGFs. PDGFs keep endothelial cells and vessels from irradiation-derived injury and provide nourishment and oxygen for malignant cells (100). PDGF-DD, one of the dimeric isoform of the PDGF family, was recently reported to be a ligand for NKp44 and trigger NK cell activation through evoking ITAM signaling and inducing phosphorylation of AKT, ERT in human NK cells (101); yet, there are no publications detailing effect of IR on other NKp44 ligands, such as MLL5, PCNA and NID1. Several studies reported that vimentin, a NKp46 ligand, increased in a variety of malignant cells in response to IR $(102,103)$. However, no studies reveal alteration of $\mathrm{NK}$ functions arising from vimentin upregulation, making it difficult to provide a view into the IR impact on NKp46 ligands.

\section{TRAIL Receptors and FAS}

IR also increases death receptors such as FAS and TRAIL on tumor cells, enhancing malignant cell destruction by NK cells. Enhanced FAS with biological activity was reported on colorectal cell lines exposed to IR (with the maximum upregulation at $10-20$ Gy) mainly due to the influences on epigenetic enzyme combination and histone acetylation $(104,105)$. Along similar lines, significant FAS induction was obtained in patients with diffuse B-cell lymphoma and early-stage breast cancer imposed to RT (106). In addition, it's reported that TRAIL receptors (DR4 and DR5) were upregulated when prostate, breast, colorectal, and lung cancer cells were exposed to IR $(21,107,108)$, suggesting a potential mechanism of NK cell mediated elimination.

\section{HLA}

Human leukocyte antigen (HLA) molecules can be divided into two subtypes: HLA class I, constitutively expressed by all somatic cells and HLA class II, only presented on antigenpresenting immune cells. HLA class I could be subdivided into classical (including HLA-A, HLA-B, and HLA-C) and nonclassical (including HLA-E, HLA-F and HLA-G) subtypes. The classical subtype is critical for NK cell inhibition and cytotoxic $\mathrm{T}$ cell activation. Several publications illustrated that IR yielded upregulation of classical HLA I, indicating a negative picture for NK cell activation. For instance, IR upregulated HLA I expression in multiple myeloma, glioblastoma and meningioma in a dosedependent manner $(109,110)$, with a peak at $12 \mathrm{~Gy}$ in brain tumors. Furthermore, an incremental dose of 0, 6, 12, and $24 \mathrm{~Gy}$ augmented HLA class I surface expression gradually in human renal clear cell carcinoma cells (111). However, HLA-G is a strong immunosuppressive molecule binding to inhibitory receptors existed on immune cells $(112,113)$, contributing to NK cell and T cell dysfunction (114-116). Previous studies illustrated that surface HLA-G1 suffered a diminish in FON melanoma cells exposed to a dose of $20 \mathrm{~Gy}$ as well as a fractionated 20 Gy irradiation $(2 \mathrm{~Gy} \times 10)(117)$. Similar results have been 
obtained with HLA-G expression on basal cell carcinomas in patients (118). HLA-E was described as a ligand capable of binding to the inhibitory CD94/NKG2A receptor on NK cells. Together with HLA-G1 expression decrease, the HLA-E level was downregulated in FON melanoma cells exposed to 10 and $20 \mathrm{~Gy}$ (117), mainly due to an indirect influence of HLA-G1 decrease induced by IR concerning the HLA-E stabilizing ability of HLAG1 molecule (119). In conclusion, IR results in the upregulation of surface HLA classic I molecules as well as diminution of HLA$\mathrm{G}$ and HLA-E molecules on which we should take advantage of increasing tumor susceptibility to NK cells.

\section{CXCL16 and HMGB1}

The upregulation of C-X-C motif ligand 16 (CXCL16) in human breast cancer cells exposed to IR resulted in a systemic surge of C-C motif chemokine receptor 6 (CCR6), expressed in NK cells through CXCL16-CCR6 interaction, which was abrogated in the presence of an anti-CXCR6 Ab (120). Additionally, a 15 Gy IR caused increased high mobility group box-1 protein (HMGB1) release in B16 melanoma cell supernatant (121), enhancing INF- $\gamma$ secretion from macrophage-stimulated NK cells (122).

\section{PD-L1}

PD-L1 immune checkpoint plays a critical role in immunodepression. The PD-1/PD-L1 pathway has been reported to modulate NK cell function versus various malignant cells in vivo and in vitro (123-125). It has been newly reported that IR increased PD-L1 expression and decreased expression of NKG2DL in radioresistant malignant cells, protecting tumor cells from NK cell cytotoxicity through the IL-6-the mitogenactivated protein kinase (MEK)/ERK pathway, which could be abrogated with the combination of PD-L1 Ab and MEK/ERK inhibitor (126).

\section{CLINICAL RESEARCH WITH REGARD TO RT ADMINISTRATION ON NK FUNCTION}

Previous reports have illustrated that RT does indeed affect the NK functional activity in cancer patients, with irradiated sites being more significant than RT doses (127-129). For instance, greater absolute NK count diminution and NK activity reduction were detected in patients who had diverse malignances delivered with IR doses ranging from 30 to 45 Gy fractionated into 15-25 schemes (single doses ranging from 1.8 to $2.5 \mathrm{~Gy}$ ), including an area of mediastinum exposure compared with those underwent treatment with other fields, while the proportion of NK cells remained stable or even higher (128). Along similar lines, breast cancer patients receiving conventional fractionated RT at 60-65 Gy (single doses ranging from 1.8 to $2.2 \mathrm{~Gy}$ ) exhibited lymphopenia and the loss of NK lytic function against K562 target cells immediately. In contrast with those who also received regional treatment, NK cell activity did not drop significantly in patients who received RT to breast only and resumed at the end of 6 weeks after RT (129). It is possible that circulating NK cells transit through the mediastinum and the more radiosensitive NK precursors in the lymph nodes are directly killed by RT. Therefore, in order to preserve NK cell functions, it would be preferred to avoid large vessels as well as unnecessary lymph node irradiation.

In breast cancer patients receiving adjuvant radiation therapy (single doses with $2 \mathrm{~Gy}$ ), significant higher number of NK cells and higher ratio of IFN- $\gamma^{+}$NK cells with increased cytotoxicity were detected even at 12 months post-RT (130). Likewise, pelvic irradiation (single doses with $2 \mathrm{~Gy}$ ) in cases of prostate cancer or seminal vesicle tumor also induced sustained proliferation of peripheral NK cells during and 3 months after RT (131). Moreover, it has been proven that the enhancement of NK proficiency facilitated the achievement of pathological complete response in cancer patients (132). These clinical observations indicate proliferation- and activation-inducing roles of RT on NK cells, providing cues of NK cell contributions to an enduring anti-tumor immune response evoked by RT.

Although a number of studies demonstrated conventional fractionated RT promoted NK cell proliferation and activation, hypofractionated RT showed contradictory results. For example, blood samples of oligometastatic breast cancer patients received stereotactic body radiotherapy (SBRT) (30 Gy in 3 fractions) to the metastatic lesions showed elevated number and activation of NK cells characterized by nuclear translocation of NF-B $24 \mathrm{~h}$ after the first dose (133). Other publications have shed light on the impact of SBRT on lung cancer. A detectable augmentation of $\mathrm{CD} 56^{\text {high }} \mathrm{CD} 16^{+} \mathrm{NK}$ cell frequency persisting throughout 6 months without statistically importance compared to baseline was observed in blood samples of lung cancer patients administrated with SBRT $(7.5 \mathrm{~Gy} \times 8$ or $12.5 \mathrm{~Gy} \times 4)(134)$. Quite the reverse occured, as another clinical research enrolling a larger cohort of lung cancer patients received a total dose ranging from 40 to $70 \mathrm{~Gy}$ fractionated into 4-10 days (single doses ranging from $6 \mathrm{~Gy}$ to $15 \mathrm{~Gy}$, with most patients received single doses ranging from $10 \mathrm{~Gy}$ to $15 \mathrm{~Gy}$ ) revealed decreased NK counts and activity immediately and at 1 week post-IR without the alteration of NK ratio in periphery (135). These divergent results may stem from different RT fraction doses, which have been proved to impact significantly on immune-related gene expressions (136). Thus, appropriate RT doses and schedules should be administered to elicit antitumor immunity (137).

To conclude, although HDIR seems to exert a negative effect on NK function in vitro, conventional fractionated RT, with no doubt, is beneficial to NK function, possibly due to the interaction between NK cells and other ingredients in the TME. In the case of SBRT, a moderate fractionated dose might be proposed for the optimal therapeutic response to both irradiated and abscopal sites. Additional factors, such as lymph node exposure, proliferative state, as well as degree of differentiation, might also occupy essential roles (138). These questions are important issues to be addressed in order to understand the radiobiology in NK cells and to determine optimal RT protocol that improves anti-tumor NK cell functions.

\section{CONCLUSION}

As a supplementary for anti-tumor $\mathrm{T}$ cell immunity, NK cells directly kill tumors without relying on antigen presentation in a major histocompatibility complex-independent way. NK 
cells have become a new tool for anti-tumor immunotherapy. Promising ingressions of engineered NK cells into clinical research have been observed in various tumors. Radiation therapy, one of the cornerstones of tumor treatment, has been verified in recent years to regulate immune system function widely with the molecular basis of radiation-activated NK cells being preliminary clarified. By modifying the NK cell biology, more research is warranted to boost NK cells against cancer in combination with IR.

\section{AUTHOR CONTRIBUTIONS}

JC, XL, QW, and CX reviewed relevant literatures and drafted the manuscript. ZZ, JL, YL, WS, YG, and JZ analyzed and

\section{REFERENCES}

1. Artis D, Spits H. The biology of innate lymphoid cells. Nature. (2015) 517:293-301. doi: 10.1038/nature14189

2. Vivier E, Raulet DH, Moretta A, Caligiuri MA, Zitvogel L, Lanier LL, et al. Innate or adaptive immunity? The example of natural killer cells. Science. (2011) 331:44-9. doi: 10.1126/science.1198687

3. Stabile H, Fionda C, Gismondi A, Santoni A. Role of distinct natural killer cell subsets in anticancer response. Front Immunol. (2017) 8:293. doi: $10.3389 /$ fimmu.2017.00293

4. Du Y, Wei Y. Therapeutic potential of natural killer cells in gastric cancer. Front Immunol. (2019) 9:3095. doi: 10.3389/fimmu.2018. 03095

5. Leong JW, Wagner JA, Ireland AR, Fehniger TA. Transcriptional and post-transcriptional regulation of $\mathrm{NK}$ cell development and function. Clin Immunol. (2017) 177:60-9. doi: 10.1016/j.clim.2016. 03.003

6. Sivori S, Vitale M, Morelli L, Sanseverino L, Augugliaro R, Bottino C, et al. p46, a novel natural killer cell-specific surface molecule that mediates cell activation. J Exp Med. (1997) 186:1129-36. doi: 10.1084/jem.186. 7.1129

7. Pende D, Parolini S, Pessino A, Sivori S, Augugliaro R, Morelli L, et al. Identification and molecular characterization of NKp30, a novel triggering receptor involved in natural cytotoxicity mediated by human natural killer cells. J Exp Med. (1999) 190:1505-16. doi: 10.1084/jem.190. 10.1505

8. Vitale M, Bottino C, Sivori S, Sanseverino L, Castriconi R, Marcenaro E, et al. NKp44, a novel triggering surface molecule specifically expressed by activated natural killer cells, is involved in non-major histocompatibility complex-restricted tumor cell lysis. J Exp Med. (1998) 187:206572. doi: $10.1084 /$ jem.187.12.2065

9. Farag SS, Caligiuri MA. Human natural killer cell development and biology. Blood Rev. (2006) 20:123-37. doi: 10.1016/j.blre.2005.10.001

10. Koch J, Steinle A, Watzl C, Mandelboim O. Activating natural cytotoxicity receptors of natural killer cells in cancer and infection. Trends Immunol. (2013) 34:182-91. doi: 10.1016/j.it.2013.01.003

11. Han C, Jiang Y, Wang Z, Wang H. Natural killer cells involved in tumour immune escape of hepatocellular carcinomar. Int Immunopharmacol. (2019) 73:10-6. doi: 10.1016/j.intimp.2019.04.057

12. Cifaldi L, Doria M, Cotugno N, Zicari S, Cancrini C, Palma P, et al. DNAM1 activating receptor and its ligands: how do viruses affect the NK cellmediated immune surveillance during the various phases of infection? Int J Mol Sci. (2019) 20:3715. doi: 10.3390/ijms20153715

13. Claus M, Meinke S, Bhat R, Watzl C. Regulation of NK cell activity by 2B4, NTB-A and CRACC. Front Biosci. (2008) 13:956-65. doi: 10.2741/ 2735

14. Del Zotto G, Marcenaro E, Vacca P, Sivori S, Pende D, Della Chiesa $\mathrm{M}$, et al. Markers and function of human NK cells in normal revised the manuscript. All authors read and approved the final version.

\section{FUNDING}

This work was supported by National Natural Science Foundation of China (81773236, 81972852, and 81803061), Health Commission of Hubei Province Medical Leading Talent Project, Health Commission of Hubei Province Scientific Research Project (WJ2019H002), Medical Science Advancement Program (Basic Medical Sciences) of Wuhan University (TFJC2018005), and Zhongnan Hospital of Wuhan University Science, Technology and Innovation Seed Fund (znpy2019070). and pathological conditions. Cytometry B Clin Cytom. (2017) 92:10014. doi: $10.1002 /$ cyto.b. 21508

15. Bi J, Tian $\mathrm{Z}$. NK cell exhaustion. Front Immunol. 8:760. doi: $10.3389 /$ fimmu.2017.00760

16. Karre K, Ljunggren HG, Piontek G, Kiessling R. Selective rejection of H-2deficient lymphoma variants suggests alternative immune defence strategy. Nature. (1986) 319:675-8. doi: 10.1038/319675a0

17. Vivier E, Tomasello E, Baratin M, Walzer T, Ugolini S. Functions of natural killer cells. Nat Immunol. (2008) 9:503-510. doi: 10.1038/ ni1582

18. Stetson DB, Mohrs M, Reinhardt RL, Baron JL, Wang Z-E, Gapin L, et al. Constitutive cytokine mRNAs mark natural killer (NK) and NK $\mathrm{T}$ cells poised for rapid effector function. J Exp Med. (2003) 198:106976. doi: $10.1084 /$ jem. 20030630

19. Wajant H, Pfizenmaier K, Scheurich P. Tumor necrosis factor signaling. Cell Death Differ. (2003) 10:45-65. doi: 10.1038/sj.cdd.4401189

20. Kayagaki N, Yamaguchi N, Nakayama M, Takeda K, Akiba H, Tsutsui H, et al. Expression and function of TNF-related apoptosis-inducing ligand on murine activated NK cells. J Immunol. (1999) 163:1906-13.

21. Screpanti V, Wallin RP, Ljunggren HG, Grandien A. A central role for death receptor-mediated apoptosis in the rejection of tumors by NK cells. J Immunol. (2001) 167:2068-73. doi: 10.4049/jimmunol.167.4.2068

22. Bradley M, Zeytun A, Rafi-Janajreh A, Nagarkatti PS, Nagarkatti M. Role of spontaneous and interleukin-2-induced natural killer cell activity in the cytotoxicity and rejection of Fas+ and Fas- tumor cells. Blood. (1998) 92:4248-55. doi: 10.1182/blood.V92.11.4248.423k20_4248_4255

23. Lanier LL. NK cell recognition. Annu Rev Immunol. (2005) 23:22574. doi: 10.1146/annurev.immunol.23.021704.115526

24. Formenti SC, Demaria S. Combining radiotherapy and cancer immunotherapy: a paradigm shift. J Nati Cancer Inst. (2013) 105:256-65. doi: 10.1093/jnci/djs629

25. Wennerberg E, Vanpouille-Box C, Bornstein S, Yamazaki T, Demaria S, Galluzzi L. Immune recognition of irradiated cancer cells. Immunol Rev. (2017) 280:220-30. doi: 10.1111/imr.12568

26. Mandai M, Hamanishi J, Abiko K, Matsumura N, Baba T, Konishi I. Dual faces of ifngamma in cancer progression: a role of PD-L1 induction in the determination of pro- and antitumor immunity. Clin Cancer Res. (2016) 22:2329-34. doi: 10.1158/1078-0432.CCR-16-0224

27. Deng L, Liang H, Burnette B, Beckett M, Darga T, Weichselbaum RR, et al. Irradiation and anti-PD-L1 treatment synergistically promote antitumor immunity in mice. J Clin Invest. (2014) 124:687-95. doi: 10.1172/JCI67313

28. Son C, Keum J, Yang K, Nam J, Kim M, Kim S, et al. Synergistic enhancement of NK cell-mediated cytotoxicity by combination of histone deacetylase inhibitor and ionizing radiation. Radiat Oncol. (2014) 9:49. doi: 10.1186/1748-717X-9-49

29. Dancea HC, Shareef MM, Ahmed MM. Role of radiation-induced TGFbeta signaling in cancer therapy. Mol Cell Pharmacol. (2009) 1:4456. doi: $10.4255 / \mathrm{mcpharmacol} .09 .06$ 
30. Wang X, Yang X, Tsai Y, Yang L, Chuang K-H, Keng PC, et al. IL6 mediates macrophage infiltration after irradiation via up-regulation of CCL2/CCL5 in Non-small cell lung cancer. Radiat Res. (2017) 187:509. doi: 10.1667/RR14503.1

31. Balogh A, Persa E, Bogdandi EN, Benedek A, Hegyesi H, Safrany G, et al. The effect of ionizing radiation on the homeostasis and functional integrity of murine splenic regulatory T cells. Inflamm Res. (2013) 62:20112. doi: 10.1007/s00011-012-0567-y

32. Xu J, Escamilla J, Mok S, David J, Priceman S, West B, et al. CSF1R signaling blockade stanches tumor-infiltrating myeloid cells and improves the efficacy of radiotherapy in prostate cancer. Cancer Res. (2013) 73:278294. doi: 10.1158/0008-5472.CAN-12-3981

33. Schueneman AJ, Himmelfarb E, Geng L, Tan J, Donnelly E, Mendel D, et al. SU11248 maintenance therapy prevents tumor regrowth after fractionated irradiation of murine tumor models. Cancer Res. (2003) 63:4009-16.

34. Lacoste-Collin L, Jozan S, Cances-Lauwers V, Pipy B, Gasset G, Caratero C, et al. Effect of continuous irradiation with a very low dose of gamma rays on life span and the immune system in SJL mice prone to B-cell lymphoma. Radiat Res. (2007) 168:725-32. doi: 10.1667/RR1007.1

35. Ina Y, Sakai K. Activation of immunological network by chronic lowdose-rate irradiation in wild-type mouse strains: analysis of immune cell populations and surface molecules. Int J Radiat Biol. (2005) 81:7219. doi: 10.1080/09553000500519808

36. Sonn CH, Choi JR, Kim T-J, Yu Y-B, Kim K, Shin SC, et al. Augmentation of natural cytotoxicity by chronic low-dose ionizing radiation in murine natural killer cells primed by IL-2. J Radiat Res. (2012) 53:8239. doi: 10.1093/jrr/rrs037

37. Yang G, Kong Q, Wang G, Jin H, Zhou L, Yu D, et al. Low-dose ionizing radiation induces direct activation of natural killer cells and provides a novel approach for adoptive cellular immunotherapy. Cancer Biother Radiopharm. (2014) 29:428-34. doi: 10.1089/cbr.2014.1702

38. Cheda A, Wrembel-Wargocka J, Lisiak E, Nowosielska EM, Marciniak M, Janiak MK. Single low doses of X rays inhibit the development of experimental tumor metastases and trigger the activities of NK cells in mice. Radiat Res. (2004) 161:335-40. doi: 10.1667/RR3123

39. Hashimoto S, Shirato H, Hosokawa M, Nishioka T, Kuramitsu Y, Matushita $\mathrm{K}$, et al. The suppression of metastases and the change in host immune response after low-dose total-body irradiation in tumor-bearing rats. Radiat Res. (1999) 151:717-24. doi: 10.2307/3580211

40. Alvarez M, Simonetta F, Baker J, Pierini A, Wenokur AS, Morrison $\mathrm{AR}$, et al. Regulation of murine NK cell exhaustion through the activation of the DNA damage repair pathway. JCI insight. (2019) 4:e127729. doi: 10.1172/jci.insight.127729

41. Huang C, Bi E, Hu Y, Deng W, Tian Z, Dong C, et al. A novel NF-кB binding site controls human granzyme $\mathrm{B}$ gene transcription. I Immunol. (2006) 176:4173-81. doi: 10.4049/jimmunol.176.7.4173

42. Zhou J, Zhang J, Lichtenheld MG, Meadows GG. A role for NF- $\kappa$ B activation in perforin expression of nk cells upon IL-2 receptor signaling. J Immunol. (2002) 169:1319-25. doi: 10.4049/jimmunol.169.3.1319

43. Clarke AJ, Simon AK. Autophagy in the renewal, differentiation and homeostasis of immune cells. Nat Rev Immunol. (2019) 19:170-83. doi: 10.1038/s41577-018-0095-2

44. Zhou L, Zhang X, Li H, Niu C, Yu D, Yang G, et al. Validating the pivotal role of the immune system in low-dose radiation-induced tumor inhibition in Lewis lung cancer-bearing mice. Cancer Med. (2018) 7:133848. doi: 10.1002/cam4.1344

45. Zarcone D, Tilden AB, Lane VG. Radiation sensitivity of resting and activated nonspecific cytotoxic cells of T lineage and NK lineage. Blood. (1989) 73:1615-21. doi: 10.1182/blood.V73.6.1615.bloodjournal7361615

46. Hietanen T, Pitkänen M. Effects of single and fractionated irradiation on natural killer cell populations: radiobiological characteristics of viability and cytotoxicity in vitro. Anticancer Res. (2015) 35:5193-200.

47. Italiani $\mathrm{P}$, Boraschi D. From monocytes to M1/M2 macrophages: phenotypical vs. functional differentiation. Front Immunol. (2014) 5:514. doi: 10.3389/fimmu.2014.00514

48. Klug F, Prakash H, Huber PE, Seibel T, Bender N, Halama N, et al. Lowdose irradiation programs macrophage differentiation to an iNOS(+)/M1 phenotype that orchestrates effective $\mathrm{T}$ cell immunotherapy. Cancer Cell. (2013) 24:589-602. doi: 10.1016/j.ccr.2013.09.014

49. Prakash H, Klug F, Nadella V, Mazumdar V, Schmitz-Winnenthal H, Umansky L. Low doses of gamma irradiation potentially modifies immunosuppressive tumor microenvironment by retuning tumorassociated macrophages: lesson from insulinoma. Carcinogenesis. (2016) 37:301-13. doi: 10.1093/carcin/bgw007

50. Li N, Karin M. Ionizing radiation and short wavelength UV activate NFkappaB through two distinct mechanisms. Proc Natl Acad Sci USA. (1998) 95:13012-7. doi: 10.1073/pnas.95.22.13012

51. Teresa Pinto A, Laranjeiro Pinto M, Patricia Cardoso A, Monteiro C, Teixeira Pinto M, Filipe Maia A, et al. Ionizing radiation modulates human macrophages towards a pro-inflammatory phenotype preserving their pro-invasive and pro-angiogenic capacities. Sci Rep. (2016) 6:18765. doi: 10.1038/srep18765

52. Bellora F, Castriconi R, Dondero A, Pessino A, Nencioni A, Liggieri G, et al. TLR activation of tumor-associated macrophages from ovarian cancer patients triggers cytolytic activity of NK cells. Eur J Immunol. (2014) 44:1814-22. doi: 10.1002/eji.201344130

53. Okubo M, Kioi M, Nakashima H, Sugiura K, Mitsudo K, Aoki I, et al. M2-polarized macrophages contribute to neovasculogenesis, leading to relapse of oral cancer following radiation. Sci Rep. (2016) 6:27548. doi: $10.1038 /$ srep27548

54. Crittenden MR, Cottam B, Savage T, Nguyen C, Newell P, Gough MJ. Expression of NF-kB p50 in tumor stroma limits the control of tumors by radiation therapy. PLoS ONE. (2012) 7:e39295. doi: 10.1371/journal.pone.0039295

55. Seifert L, Werba G, Tiwari S, Giao Ly NN, Nguy S, Alothman S, et al. Radiation therapy induces macrophages to suppress t-cell responses against pancreatic tumors in Mice. Gastroenterology. (2016) 150:165972. doi: $10.1053 /$ j.gastro.2016.02.070

56. Peng L, Zhang J, Teng Y, Zhao Y, Wang T, Mao F, et al. Tumorassociated monocytes/ macrophages impair NK-cell function via TGFß1 in human gastric cancer. Cancer Immunol Res. (2017) 5:248-57. doi: 10.1158/2326-6066.CIR-16-0152

57. Krneta T, Gillgrass A, Poznanski S, Chew M, Lee AJ, Kolb M, et al. M2polarized and tumor-associated macrophages alter NK cell phenotype and function in a contact-dependent manner. J Leukoc Biol. (2017) 101:28595. doi: 10.1189/jlb.3A1215-552R

58. Wu Y, Kuang D, Pan W, Wan Y, Lao X, Wang D, et al. Monocyte/macrophage-elicited natural killer cell dysfunction in hepatocellular carcinoma is mediated by CD48/2B4 Interactions. Hepatology. (2012) 57:1107-1116. doi: 10.1002/hep.26192

59. Sakaguchi S. Naturally arising Foxp3-expressing CD25+CD4+ regulatory T cells in immunological tolerance to self and non-self. Nat Immunol. (2005) 6:345-52. doi: 10.1038/nil178

60. Suvas S, Kumaraguru U, Pack CD, Lee S, Rouse BT. CD4+CD25+ $\mathrm{T}$ cells regulate virus-specific primary and memory CD8+ $\mathrm{T}$ cell responses. J Exp Med. (2003) 198:889-901. doi: 10.1084/jem. 20030171

61. Chen W, Jin W, Hardegen N, Lei K, Li L, Marinos N, et al. Conversion of peripheral CD4+CD25- naive $\mathrm{T}$ cells to $\mathrm{CD} 4+\mathrm{CD} 25+$ regulatory $\mathrm{T}$ cells by TGF- $\beta$ induction of transcription factor Foxp3. J Exp Med. (2003) 198:1875-86. doi: 10.1084/jem.20030152

62. Terme M, Pernot S, Marcheteau E, Sandoval F, Benhamouda N, Colussi O, et al. VEGFA-VEGFR pathway blockade inhibits tumor-induced regulatory T-cell proliferation in colorectal cancer. Cancer Res. (2013) 73:53949. doi: 10.1158/0008-5472.CAN-12-2325

63. Schaue D, Ratikan JA, Iwamoto KS, McBride WH. Maximizing tumor immunity with fractionated radiation. Int J Radiat Oncol Biol Phys. (2012) 83:1306-10. doi: 10.1016/j.ijrobp.2011.09.049

64. Qu Y, Zhang B, Liu S, Zhang A, Wu T, Zhao Y. 2-Gy whole-body irradiation significantly alters the balance of CD4+CD25- T effector cells and CD4+CD25+Foxp3+ T regulatory cells in mice. Cell Mol Immunol. (2010) 7:419-27. doi: $10.1038 / \mathrm{cmi} .2010 .45$

65. Janakiram NB, Mohammed A, Bryant T, Brewer M, Biddick L, Lightfoot $\mathrm{S}$, et al. Adoptive transfer of regulatory $\mathrm{T}$ cells promotes intestinal tumorigenesis and is associated with decreased NK cells and 
IL-22 binding protein. Mol Carcinog. (2015) 54:986-98. doi: 10.1002/mc. 22168

66. Ghiringhelli F, Martin F. The role of regulatory $\mathrm{T}$ cells in the control of natural killer cells: relevance during tumor progression. Immunol Rev. (2006) 214:229-38. doi: 10.1111/j.1600-065X.2006. 00445.x

67. Zhdanov DD, Gladilina YA, Pokrovsky VS, Grishin DV, Grachev VA, Orlova VS, et al. Murine regulatory $\mathrm{T}$ cells induce death of effector T, B, and NK lymphocytes through a contact-independent mechanism involving telomerase suppression and telomere-associated senescence. Cell Immunol. (2018) 331:146-60. doi: 10.1016/j.cellimm.2018. 06.008

68. Frey AB. Myeloid suppressor cells regulate the adaptive immune response to cancer. J Clin Invest. (2006) 116:2587-90. doi: 10.1172/JCI 29906

69. Bruno A, Mortara L, Baci D, Noonan DM, Albini A. Myeloid derived suppressor cells interactions with natural killer cells and proangiogenic activities: roles in tumor progression. Front Immunol. (2019) 10:771. doi: 10.3389/fimmu.2019.00771

70. Talebian M, Schinkelshoek MS, Loof NM, Taube C, Hiemstra PS. Standard radiotherapy but not chemotherapy impairs systemic immunity in non-small cell lung cancer. Oncoimmunology. (2016) 5:e1255393. doi: 10.1080/2162402X.2016.12 55393

71. Elkabets M, Ribeiro VSG, Dinarello CA, Ostrand-Rosenberg S, Di Santo JP, Apte RN, et al. IL-1beta regulates a novel myeloidderived suppressor cell subset that impairs NK cell development and function. Eur J Immunol. (2010) 40:3347-3357. doi: 10.1002/eji.2010 41037

72. Li H, Han Y, Guo Q, Zhang M, Cao X. Cancer-expanded myeloidderived suppressor cells induce anergy of nk cells through membranebound TGF- $\beta 1$. J Immunol. (2009) 182:240-9. doi: 10.4049/jimmunol. 182.1.240

73. Hoechst B, Voigtlaender T, Ormandy L, Gamrekelashvili J, Zhao F, Wedemeyer $\mathrm{H}$, et al. myeloid derived suppressor cells inhibit natural killer cells in patients with hepatocellular carcinoma via the NKp30 receptor. Hepatology. (2019) 50:799-807. doi: 10.1002/hep.23054

74. Vaknin I, Blinder L, Wang L, Gazit R, Shapira E, Genina O, et al. A common pathway mediated through Toll-like receptors leads to T- and natural killer-cell immunosuppression. Blood. (2008) 111:143747. doi: 10.1182/blood-2007-07-100404

75. Steinman RM. Decisions about dendritic cells: past, present, and future. Annu Rev Immunol. (2012) 30:122. doi: 10.1146/annurev-immunol-100311-102839

76. Yu N, Wang S, Song X, Gao L, Li W, Yu H, et al. Low-dose radiation promotes dendritic cell migration and IL-12 production via the ATM/NFKappaB pathway. Radiat Res. (2018) 189:409-17. doi: 10.1667/RR14840.1

77. Shigematsu A, Adachi Y, Koike-Kiriyama N, Suzuki Y, Iwasaki M, Koike $\mathrm{Y}$, et al. Effects of low-dose irradiation on enhancement of immunity by dendritic cells. J Radiat Res. (2007) 48:51-5. doi: 10.1269/jrr.06048

78. Vujanovic L, Szymkowski DE, Alber S, Watkins SC, Vujanovic NL, Butterfield LH. Virally infected and matured human dendritic cells activate natural killer cells via cooperative activity of plasma membrane-bound TNF and IL-15. Blood. (2010) 116:575-83. doi: 10.1182/blood-2009-08240325

79. Merrick A, Errington F, Milward K, Donnell DO, Harrington K, Bateman A, et al. Immunosuppressive effects of radiation on human dendritic cells: reduced IL-12 production on activation and impairment of na ive T-cell priming. Br J Cancer. (2005) 92:1450-58. doi: 10.1038/sj.bjc.6602518

80. Fuchs A, Vermi W, Lee JS, Lonardi S, Gilfillan S, Newberry RD, et al. Intraepithelial type 1 innate lymphoid cells are a unique subset of IL12- and IL-15-responsive IFN-gamma-producing cells. Immunity. (2013) 38:769-81. doi: 10.1016/j.immuni.2013.02.010

81. Kim J, Bae J-S. Tumor-associated macrophages and neutrophils in tumor microenvironment. Mediators Inflamm. (2016) 2016:6058147. doi: 10.1155/2016/6058147

82. Fridlender ZG, Sun J, Kim S, Kapoor V, Cheng G, Worthen GS, et al. Polarization of tumor-associated neutrophil (TAN) phenotype by TGF- $\beta$ : “N1" versus “N2" TAN. Cancer Cell. (2009) 16:183-94. doi: 10.1016/j.ccr.2009.06.017

83. Spiegel A, Brooks MW, Houshyar S, Reinhardt F, Ardolino M, Fessler E, et al. Neutrophils suppress intraluminal NK-mediated tumor cell clearance and enhance extravasation of disseminated carcinoma cells. Cancer Discov. (2016) 6:630-49. doi: 10.1158/2159-8290.CD-15-1157

84. Dhar P, Wu JD. NKG2D and its ligands in cancer. Curr Opin Immunol. (2018) 51:55-61. doi: 10.1016/j.coi.2018.02.004

85. Lee YS, Heo W, Nam J, Jeung YH, Bae J. The combination of ionizing radiation and proteasomal inhibition by bortezomib enhances the expression of NKG2D ligands in multiple myeloma cells. J Radiat Res. (2018) 59:24552. doi: 10.1093/jrr/rry005

86. Gasser S, Orsulic S, Brown EJ, Raulet DH. The DNA damage pathway regulates innate immune system ligands of the NKG2D receptor. Nature. (2005) 436:1186-90. doi: 10.1038/nature03884

87. Weiss $T$, Schneider $H$, Silginer $M$, Steinle $A$, Weller $M$, Roth $\mathrm{P}$, et al. NKG2D-dependent antitumor effects of chemotherapy and radiotherapy against glioblastoma. Clin Cancer Res. (2018) 24:882-96. doi: 10.1158/1078-0432.CCR-17-1766

88. Zhang J, Basher F, Wu JD. NKG2D Ligands in tumor immunity: two sides of a coin. Front Immunol. (2015) 6:97. doi: 10.3389/fimmu.2015.00097

89. Groh V, Wu J, Yee C, Spies T. Tumour-derived soluble MIC ligands impair expression of NKG2D and T-cell activation. Nature. (2002) 419:73438. doi: 10.1038/nature01112

90. Heo W, Lee YS, Son CHUN, Yang K, Park YOUSOO, Bae J. Radiationinduced matrix metalloproteinases limit natural killer cell-mediated anticancer immunity in NCI-H23 lung cancer cells. Mol Med Rep. (2015) 11:1800-6. doi: 10.3892/mmr.2014.2918

91. Pogge von Strandmann E, Shatnyeva O, Hansen HP. NKp30 and its ligands: emerging players in tumor immune evasion from natural killer cells. Ann Transl Med. (2015) 3:314. doi: 10.3978/j.issn.2305-5839.2015.09.08

92. Parodi M, Favoreel H, Candiano G, Gaggero S, Sivori S, Mingari MC, et al. NKp44-NKp44 ligand interactions in the regulation of natural killer cells and other innate lymphoid cells in humans. Front Immunol. (2019) 10:719. doi: 10.3389/fimmu.2019.00719

93. Wang W, Guo H, Geng J, Zheng X, Wei H, Sun R, et al. Tumor-released Galectin-3, a soluble inhibitory ligand of human NKp30, plays an important role in tumor escape from NK cell attack. J Biol Chem. (2014) 289:333119. doi: 10.1074/jbc.M114.603464

94. Radosavljevic G, Jovanovic I, Majstorovic I, Mitrovic M, Lisnic VJ, Arsenijevic N, et al. Deletion of galectin-3 in the host attenuates metastasis of murine melanoma by modulating tumor adhesion and NK cell activity. Clin Exp Metastasis. (2011) 28:451-62. doi: 10.1007/s10585-011-9383-y

95. Conti S, Vexler A, Hagoel L, Kalich-philosoph L, Corn BW, Honig $\mathrm{N}$, et al. Modified citrus pectin as a potential sensitizer for radiotherapy in prostate cancer. Integr Cancer Ther. (2018) 17:1225-34. doi: 10.1177/1534735418790382

96. Brandt CS, Baratin M, Yi EC, Kennedy J, Gao Z, Fox B, et al. The B7 family member B7-H6 is a tumor cell ligand for the activating natural killer cell receptor NKp30 in humans. J Exp Med. (2009) 206:14951503. doi: 10.1084/jem.20090681

97. Chen Y, Mo J, Jia X, He Y. The B7 family member B7-H6: a new bane of tumor. Pathol Oncol Res. (2018) 24:717-21. doi: 10.1007/s12253-017-0357-5

98. Arnon TI, Achdout H, Levi O, Markel G, Saleh N, Katz G, et al. Inhibition of the NKp30 activating receptor by pp65 of human cytomegalovirus. Nat Immunol. (2005) 6:515-523. doi: 10.1038/ni1190

99. Cao G, Wang J, Zheng X, Wei H, Tian Z, Sun R. Tumor therapeutics work as stress inducers to enhance tumor sensitivity to natural Killer (NK) cell cytolysis by up-regulating NKp30 Ligand B7-H6. J Biol Chem. (2015) 290:29964-73. doi: 10.1074/jbc.M115.674010

100. Li M, Jendrossek V, Belka C. The role of PDGF in radiation oncology. Radiat Oncol. (2007) 2:5. doi: 10.1186/1748-717X-2-5

101. Barrow AD, Edeling MA, Trifonov V, Luo J, Goyal P, Bohl B, et al. Natural killer cells control tumor growth by sensing a growth factor. Cell. (2018) 172:534-48. doi: 10.1016/j.cell.2017.11.037

102. Priesch-grzeszkowiak B, Hero T. Robol and vimentin regulate radiationinduced motility of human glioblastoma cells. PLoS ONE. (2018) 13:e0198508. doi: 10.1371/journal.pone.0198508 
103. Kim EH, Kim M, Furusawa Y, Uzawa A, Han S. Metformin enhances the radiosensitivity of human liver cancer cells to $\gamma$-rays and carbon ion beams. Oncotarget. (2016) 7:80568-78. doi: 10.18632/oncotarget. 12966

104. Chakraborty M, Abrams SI, Camphausen K, Liu K, Scott T, Coleman CN, et al. Irradiation of tumor cells up-regulates fas and enhances CTL lytic activity and CTL adoptive immunotherapy. J Immunol. (2003) 170:633847. doi: 10.4049/jimmunol.170.12.6338

105. Cacan E, Greer SF, Garnett-benson C. Radiation-induced modulation of immunogenic genes in tumor cells is regulated by both histone deacetylases and DNA methyltransferases. Int J Oncol. (2015) 47:226475. doi: 10.3892/ijo.2015.3192

106. Horton JK, Siamakpour-reihani S, Lee C, Zhou Y, Chen W, Geradts J, et al. FAS death receptor: a breast cancer subtype-specific radiation response biomarker and potential therapeutic target. Radiat Res. (2015) 184:45669. doi: 10.1667/RR14089.1

107. Shankar S, Singh TR, Srivastava RK. Ionizing radiation enhances the therapeutic potential of TRAIL in prostate cancer in vitro and in vivo: Intracellular mechanisms. Prostate. (2004) 61:35-49. doi: 10.1002/pros. 20069

108. Marini P, Schmid A, Jendrossek V, Faltin H, Daniel PT, Budach $\mathrm{W}$, et al. Irradiation specifically sensitises solid tumour cell lines to TRAIL mediated apoptosis. BMC Cancer. (2005) 5:5. doi: 10.1186/14712407-5-5

109. Chiriva-Internati M, Grizzi F, Pinkston J, Morrow KJ, D’Cunha N, Frezza EE, et al. Gamma-radiation upregulates MHC class I/II and ICAM-I molecules in multiple myeloma cell lines and primary tumors. In Vitro Cell Dev Biol Anim. (2006) 42:89-95. doi: 10.1290/0508054.1

110. Rosental B, Appel MY, Yossef R, Hadad U, Brusilovsky M, Porgador A. The effect of chemotherapy/radiotherapy on cancerous pattern recognition by NK cells. Curr Med Chem. (2012) 19:1780-91. doi: 10.2174/092986712800099730

111. Ma Z, Huang J, Cui N, Wen M, Chen B, Li Z, et al. Expressions of immunogenic molecules in low-dose radiotherapy-treated human renal clear cell carcinoma 786-0 cells. Zhonghua Yi Xue Za Zhi. (2013) 93: 2385-7.

112. Carosella ED, Moreau P, Le Maoult J, Le Discorde M, Dausset J, RouasFreiss N. HLA-G molecules: from maternal-fetal tolerance to tissue acceptance. Adv Immunol. (2003) 81:199-252. doi: 10.1016/S0065-2776(03) 81006-4

113. Colonna M, Navarro F, Bellon T, Llano M, Garcia P, Samaridis J, et al. A common inhibitory receptor for major histocompatibility complex class I molecules on human lymphoid and myelomonocytic cells. J Exp Med. (1997) 186:1809-18. doi: 10.1084/jem.186.11.1809

114. Kapasi K, Albert SE, Yie S, Zavazava N, Librach CL. HLA-G has a concentration-dependent effect on the generation of an allo-CTL response. Immunology. (2000) 101:191-200. doi: 10.1046/j.1365-2567.2000. 00109.x

115. LeMaoult J, Krawice-Radanne I, Dausset J, Carosella ED. HLAG1-expressing antigen-presenting cells induce immunosuppressive CD4+ T cells. Proc Natl Acad Sci USA. (2004) 101:70647069. doi: 10.1073/pnas.0401922101

116. Chen LJ, Han ZQ, Zhou H, Zou L, Zou P. Inhibition of HLA-G expression via RNAi abolishes resistance of extravillous trophoblast cell line TEV-1 to NK lysis. Placenta. (2010) 31:519-27. doi: 10.1016/j.placenta.2010.03.008

117. Michelin S, Gallegos CE, Dubner D, Favier B, Carosella ED. Ionizing radiation modulates the surface expression of human leukocyte antigen$\mathrm{G}$ in a human melanoma cell line. Hum Immunol. (2009) 70:101015. doi: 10.1016/j.humimm.2009.07.030

118. Urosevic M, Kempf W, Zagrodnik B, Panizzon R, Burg G, Dummer R. HLA$\mathrm{G}$ expression in basal cell carcinomas of the skin recurring after radiotherapy. Clin Exp Dermatol. (2005) 30:422-5. doi: 10.1111/j.1365-2230.2005. 01790.x

119. Braud VM, Allan DS, O'Callaghan CA, Soderstrom K, D’Andrea A, Ogg GS, et al. HLA-E binds to natural killer cell receptors CD94/NKG2A, B and C. Nature. (1998) 391:795-9. doi: 10.1038/35869

120. Yoon MEESUN, Pham CTIN, Phan MTHI, Shin D, Jang Y, Park $\mathrm{M}$, et al. Irradiation of breast cancer cells enhances CXCL16 ligand expression and induces the migration of natural killer cells expressing the CXCR6 receptor. Cytotherapy. (2016) 18:1532-42. doi: 10.1016/j.jcyt.2016. 08.006

121. Finkel P, Frey B, Mayer F, Bösl K, Werthmöller N, Mackensen $A$, et al. The dual role of $\mathrm{NK}$ cells in antitumor reactions triggered by ionizing radiation in combination with hyperthermia. Oncoimmunology. (2016) 5:e1101206. doi: 10.1080/2162402X.2015. 1101206

122. DeMarco RA, Fink MP, Lotze MT. Monocytes promote natural killer cell interferon gamma production in response to the endogenous danger signal HMGB1. Mol Immunol. (2005) 42:433-44. doi: 10.1016/j.molimm.2004.07.023

123. Benson DMJ, Bakan CE, Mishra A, Hofmeister CC, Efebera Y, Becknell B, et al. The PD-1/PD-L1 axis modulates the natural killer cell versus multiple myeloma effect: a therapeutic target for CT-011, a novel monoclonal anti-PD-1 antibody. Blood. (2010) 116:2286-2294. doi: 10.1182/blood-2010-02-271874

124. Huang BY, Zhan YP, Zong WJ, Yu CJ, Li JF, Qu YM, et al. The PD-1/B7-H1 pathway modulates the natural killer cells versus mouse glioma stem cells. PLoS ONE. (2015) 10:e0134715. doi: 10.1371/journal.pone.0134715

125. Concha-Benavente F, Srivastava RM, Trivedi S, Lei Y, Chandran $\mathrm{U}$, Seethala RR, et al. Identification of the cell-intrinsic and extrinsic pathways Downstream of EGFR and IFN $\gamma$ that induce PD-L1 expression in head and neck cancer. Cancer Res. (2016) 76:1031-43. doi: 10.1158/0008-5472.CAN-15-2001

126. Shen MJ, Xu LJ, Yang L, Tsai Y, Keng PC, Chen Y, et al. Radiation alters PDL1/NKG2D ligand levels in lung cancer cells and leads to immune escape from NK cell cytotoxicity via IL-6-MEK/Erk signaling pathway. Oncotarget. (2017) 8:80506-20. doi: 10.18632/oncotarget.19193

127. Oesterich L, Schlom J, Donahue R, Valicenti RK, Canter RJ, Maverakis EM. Stereotactic ablative radiotherapy induces systemic differences in peripheral blood immunophenotype dependent on irradiated site. Int $J$ Radiat Oncol Biol Phys. (2018) 101:1259-1270. doi: 10.1016/j.ijrobp.2018. 04.038

128. McGinnes K, Florence J, Penny R. The effect of radiotherapy on the natural killer (NK)-cell activity of cancer patients. J Clin Immunol. (1987) 7:210217. doi: 10.1007/BF00915726

129. Standish LJ, Torkelson C, Hamill FA, Yim D, Hill-Force A, Fitzpatrick A, et al. Immune defects in breast cancer patients after radiotherapy. J Soc Integr Oncol. (2008) 6:110-121.

130. Moza F, Christina V, Aniruddha L, Mats HG, Bo L, Anders MO, et al. Systemic immune effects of adjuvant chemotherapy with 5-fluorouracil, epirubicin and cyclophosphamide and/or radiotherapy in breast cancer: a longitudinal study. Cancer Immunol Immunother. (2009) 58:111120. doi: 10.1007/s00262-008-0530-5

131. Eckert F, Schaedle P, Zips D, Schmid-horch B, Rammensee H, Gani $\mathrm{C}$, et al. Impact of curative radiotherapy on the immune status of patients with localized prostate cancer. Oncoimmunology. (2018) 7:e1496881. doi: 10.1080/2162402X.2018.1496881

132. Muraro E, Comaro E, Talamini R, Turchet E, Miolo G, Scalone S, et al. Improved Natural Killer cell activity and retained anti-tumor CD8(+) $\mathrm{T}$ cell responses contribute to the induction of a pathological complete response in HER2-positive breast cancer patients undergoing neoadjuvant chemotherapy. J Transl Med. (2015) 13:204. doi: 10.1186/s12967-0150567-0

133. Fields RC, Muraro E. Local High-Dose Radiotherapy Induces Systemic Immunomodulating Effects of Potential Therapeutic Relevance in Oligometastatic Breast Cancer. Front Immunol. (2017) 8:1476. doi: 10.3389/fimmu.2017.01476

134. Navarro-mart A, Galiana IL, Frances MAB, Cacicedo J, Cañas R, Anton SC, et al. Preliminary Study of the Effect of Stereotactic Body Radiotherapy (SBRT) on the Immune System in Lung Cancer Patients Unfit for Surgery: Immunophenotyping Analysis. Int J Mol Sci. (2018) 19:3963. doi: 10.3390/ijms19123963

135. Maehata Y, Onishi H, Kuriyama K, Aoki S, Araya M, Saito R, et al. Immune Responses following Stereotactic Body Radiotherapy for Stage I Primary Lung Cancer. Biomed Res Int. (2013) 2013:731346. doi: 10.1155/2013/ 731346 
136. Vanpouille-box C, Alard A, Aryankalayil MJ, Sarfraz Y, Diamond JM, Schneider RJ, et al. DNA exonuclease Trex1 regulates radiotherapy-induced tumour immunogenicity. Nat Commun. (2017) 8:15618. doi: $10.1038 /$ ncomms 15618

137. Deutsch E, Chargari C, Galluzzi L, Kroemer G. Optimising efficacy and reducing toxicity of anticancer radioimmunotherapy. Lancet Oncol. (2019) 20:e452-63. doi: 10.1016/S1470-2045(19)30171-8

138. Rodriguez-ruiz ME, Vitale I, Harrington KJ, Melero I, Galluzzi L. Immunological impact of cell death signaling driven by radiation on the tumor microenvironment. Nat Immunol. (2020) 21:120-34. doi: 10.1038/s41590-019-0561-4
Conflict of Interest: The authors declare that the research was conducted in the absence of any commercial or financial relationships that could be construed as a potential conflict of interest.

Copyright $\odot 2020$ Chen, Liu, Zeng, Li, Luo, Sun, Gong, Zhang, Wu and Xie. This is an open-access article distributed under the terms of the Creative Commons Attribution License (CC BY). The use, distribution or reproduction in other forums is permitted, provided the original author(s) and the copyright owner(s) are credited and that the original publication in this journal is cited, in accordance with accepted academic practice. No use, distribution or reproduction is permitted which does not comply with these terms. 